\title{
THE PREVENTION OF IMPENDING CARDIAC INFARCTION BY ANTICOAGULANT TREATMENT
}

BY

\author{
K. SHIRLEY SMITH, Resident Medical Officer, National Heart Hospital, 1927, AND \\ CORNELIO PAPP, Clinical Assistant to Dr. John Parkinson, National Heart Hospital, 1940-47 \\ From the Cardiac Department, Charing Cross Hospital \\ Received June 12, 1951
}

While there are reasons for believing that anticoagulants are valuable in the treatment of cardiac infarction, their use in preventing the disease has remained more debatable. It is our purpose in the present study to examine the possibility of forestalling acute coronary occlusion by the administration of heparin or dicoumarol or both during the phase of premonitory symptoms. The evidence based upon animal experiment and clinical work will be reviewed; our own group of successfully treated patients will be described and contrasted with a comparable group in which this treatment failed in its purpose. Reference will also be made to the unusual cases in which patients suffering from coronary disease present (sometimes repeatedly) the prodromal symptoms without developing the expected sequel of infarction, even though no anticoagulant treatment be given.

Since the earliest clinical studies of cardiac infarction it has been recognized that while the illness often comes without warning there are instances in which premonitory pains foreshadow the event. At a time when the clinical recognition of cardiac infarction was infrequent, Wearn (1923) wrote that " the onset may occur after a number of anginal attacks which, together with the dyspnœa, may constitute the only previous warnings of involvement of the coronary arteries." A year or two later Kahn (1926), Parkinson and Bedford (1928), and Levine (1929) drew attention to the same fact. Since then the published references to prodromal pain have been numerous; they include those of Willius (1936), Feil (1937), Sampson and Eliaser (1937), Brill (1938), and Plotz (1944). Behrmann et al. (1950) listed the modes of onset of cardiac infarction and indicated that premonitory pain must be due to rapidly forming thrombus or subintimal hæmorrhage with fairly rapid occlusion of a coronary artery. More recently Mounsey (1951) has laid down the criteria for acceptance of symptoms as " prodromal " and has recounted the clinical and cardiographic features of this state. His findings support the concept of a gradually decreasing coronary lumen with increasing myocardial ischæmia as the cause of the pain terminating in infarction. He claims that the fatality rate is lower among patients who show prodromal symptoms than among those who do not.

\section{USE OF ANTICOAGULANTS IN MYOCARDIAL ISCHÆMIA}

The use of heparin and dicoumarol in the treatment of some cases of infarction is now well established in cardiological practice. There are still those who are sceptical as to the value of such treatment and there are yet others who would treat almost every case with these drugs. The ideal probably lies somewhere between these extremes. Shirley Smith (1950) and Papp and Shirley Smith (1951) have included among the purposes of anticoagulant therapy in coronary disease " the aim of preventing cardiac infarction when pain of increasing severity or frequency seems to threaten this development." Wright (1949) has employed anticoagulants over long periods in ambulant patients and considers that recurrent coronary thrombosis with myocardial infarction is an indication for such treatment. It has been found that therapeutic doses of dicoumarol have no effect upon 
sedimentation rate in normal ambulatory subjects (Palmer and Gunderson, 1948; Hyman and Harris, 1950); this test therefore retains its diagnostic value during treatment in helping to decide whether or not cardiac infarction has supervened. It has to be remembered also that heparin may act not only by hindering coagulation of the blood but also by causing direct vaso-dilatation, as shown by Abrahams and Howarth (1950).

\section{Use of Anticoagulants to Prevent Vascular Thrombosis}

The production of heparin in a form sufficiently pure for therapeutic use synchronized with its use on experimental animals to determine its value in preventing coronary thrombosis. Solandt and Best (1938) found that the introduction of sodium ricinoleate into the coronary artery of a dog would produce occlusion in 20 hours and that this could be prevented by the intravenous injection of highly purified heparin prior to the introduction of sodium ricinoleate into the lumen of the coronary artery. They emphasized that heparin might have therapeutic possibilities in acute coronary crises if it were not for the absence of premonitory signs of these conditions.

The value of anticoagulants in the prevention of post-operative thrombosis and embolism was demonstrated by Allen et al. (1947). Large-scale investigations on anticoagulants in the treatment of cardiac infarction were undertaken (Parker and Barker, 1948; Wright et al., 1948) in the following year. Even before these studies the first attempts to forestall acute coronary thrombosis by these substances had been made by Nichol and Fassett (1947), who gave an account of five patients who after having had multiple myocardial infarctions were given dicoumarol continuously for periods of 6 to 33 months with improvement in the angina and without further coronary occlusion while effective doses were maintained. Similar results have since been described on larger series by Nichol and Borg (1950).

The syndrome of angina pectoris gravis acuta or protracted coronary insufficiency prodromal of infarction has been described by Holtzman (1948); in one case he made an unsuccessful attempt to prevent cardiac infarction by the use of heparin and dicoumarol. Earlier workers (Cotlove and Vorzimer, 1946) had also been disappointed in the use of dicoumarol in this condition, remarking that it was " probably of no value in preventing or minimizing coronary thrombosis." Similarly, Reich and Eisenmenger (1948) reported two cases in which new coronary involvement occurred while the patients were kept at an effective prothrombin level with dicoumarol; they concluded that the main use of this substance in this disease was in preventing thrombo-embolic complications. Wood (1949) treated 10 patients with angina at rest by heparin and dicoumarol in the hope of preventing cardiac,infarction: there was recovery in 8 without infarction while the other 2 died from cardiac causes three or four weeks after the cessation of treatment; these results were better than those in 9 controls treated without anticoagulants. This author holds (Wood, 1950) that in some patients a reasonably sure diagnosis of impending cardiac infarction may be made and that treatment by anticoagulants should be started immediately.

\section{Basis of Present InVestigation}

An unselected group of 200 patients observed during the past three years with cardiac infarction has been reviewed from the standpoint of the frequency of premonitory pain. A group of 30 patients were found to have had such symptoms; of these, 12 had slight, 6 had moderate, and 12 had severe cardiac infarction. Six of the thirty patients died and five of them belonged, as might be expected, to the group of severe infarction. The 20 per cent mortality among the patients with prodromal syndromes differed little from the 25 per cent mortality among the total series of 200 patients. In the available comparable series from other sources the fatality rate in the prodromal group has in each instance been lower than in the group without premonitory symptoms.

Apart from the foregoing series there were 14 other patients who seemed to be about to develop cardiac infarction; they were patients in whom the angina was showing a different pain pattern and the pain was losing its relation to effort and was becoming more frequent or severe. These 
were given anticoagulant treatment by heparin and dicoumarol: the heparin was given in doses of 25,000 units daily for the first two to three days and thereafter dicoumarol or tromexan; occasionally tromexan alone was employed. In seven instances cardiac infarction did not ensue and a study of the case histories here briefly recounted suggests that this favourable course was secured by means of anticoagulant treatment.

Case 1. A man, aged 68, had effort angina for several weeks. Clinical and radiological examinations showed no abnormality. Cardiography showed small T in V6 and abnormally shaped T waves in leads II and V4. Five weeks rest in bed was unavailing, the attacks gradually increasing in frequency up to five and six daily. Attacks mostly lasted a few minutes and some were relieved by trinitrin; sedatives and aminophylin were ineffective. Heparin and dicoumarol were started on 18/12/50 and the latter was continued till $8 / 1 / 51$. The prothrombin time was still $32 / 17$ on $13 / 1 / 51$, and no difficulty had been met in maintaining it stable. On the first night after starting treatment there was only one attack; on the third day there was one attack: solitary bouts recurred on the fourth, seventh, and tenth days but thereafter pain did not recur and the patient left hospital on 15/1/51 after a stay of a month. The cardiogram had become normal on $29 / 12 / 50$ (Fig. 1). Up to $29 / 1 / 51$ there had been no further pain; on $7 / 3 / 51$ after being back at work for three weeks there had been only three slight pains in the past fourteen days: pain had recurred twice while climbing stairs but had subsided immediately without trinitrin.

Case 2. A dental surgeon, aged 58 and overweight, was known to have had left bundle branch block for several years. On 25/9/49 while at rest he had a severe bout of pain across the upper part of the chest and spreading to the shoulders and arms. Cardiogram unchanged; B.P. 150/90 (as previously). Attacks became more frequent and severe and began to occur at night. Put to bed on $1 / 10 / 49$, and 20 hours later had a very severe pain lasting 50 minutes. Treatment with tromexan started and continued for three weeks; there was no recurrence of pain and the blood pressure and cardiogram remained unaltered. $\mathrm{He}$ subsequently returned to work and was reported as making steady, slow improvement.

Case 3. An engineer surveyor, aged 55, had infrequent angina of effort for four years until August, 1950; during four or five weeks the pains worsened and finally recurred almost every day. B.P. averaged 205/95. Cardiogram showed in leads I, II and V4-V6 small upright T waves with 1-2 mm., S-T depression; $2 \mathrm{~mm}$. elevation of S-T in V2 (Fig. 2A). Confinement to bed for a fortnight brought no improvement and a week later he could not walk 100 yards without pain. Graph unchanged, except slight coving of S-T in I and in V4 deeper S-T depression with diphasic T wave; in V6 there was S-T depression and coving. The appearances were similar to those of a positive effort test (Fig. 2B). He was admitted to hospital on 27/10/50 and tromexan started on the same day. Chest pain disappeared after a day or two and he remained free except for one night attack until treatment ceased on 19/11/50. E.S.R. normal throughout. Cardiogram at this time showed reversion towards normal but aVL (taken for first time) was abnormal (Fig. 2C). On. $7 / 12 / 50$ he had had no return of pain though walking half a mile. Cardiogram unchanged; B.P. 175/105.

Case 4. A clerk, aged 50, was seen on 5/9/49 when for six weeks he had been troubled with angina pectoris. B.P. 165/105. Cardiogram normal. He rested at home for three weeks but although he increased his activity very gradually his condition worsened so that on 22/11/49 he was unable to walk 50 yards without pain and was getting frequent attacks at rest. Graph showed S-T elevation of $1.5 \mathrm{~mm}$. in lead II and $1 \mathrm{~mm}$. in III; T wave small in V6. He was admitted to hospital three days later and anticoagulant treatment started; the blood pressure fell to 105/75 during the first week; thereafter it rose gradually to $130 / 80$ at the time of discharge on 21/12/49. Cardiogram unchanged. Slight nocturnal pains were felt during the first week in hospital but he was discharged free from angina. Follow up, 31/5/51: active all the time; only occasional pain when hurrying up inclines which subsides as soon as he stops.

Case 5. A business woman, aged 55, had suffered from hypertension (210/115-170/100) for years. She had also healed pulmonary tuberculosis and subsequent bronchial asthma. On 29/10/50 she had her first attack of angina while walking; this recurred during succeeding two days and nocturnal attacks developed. B.P. 205/105. Cardiogram, slight ischæmic changes; notably suppression of $T$ wave in aVL (Fig. 3A). On 7/11/50 she still complained of frequent daily and nocturnal attacks, although resting in bed at home. New cardiogram showed S-T depressions in leads II, V3, and V5 (Fig. 3B). Admitted to hospital on 9/11/50 and treated from that day until 30/12/50 with heparin and later tromexan. No pain during the stay in hospital although up and about in the ward after the second week. Cardiogram showed regression of ischæmic patterns but $T$ had become inverted in aVL (Fig. 3C). Reviewed on 26/1/51 and 27/5/51: there had been no recurrence of pain whatsoever; she was able to walk carrying her own shopping and free from symptoms. 


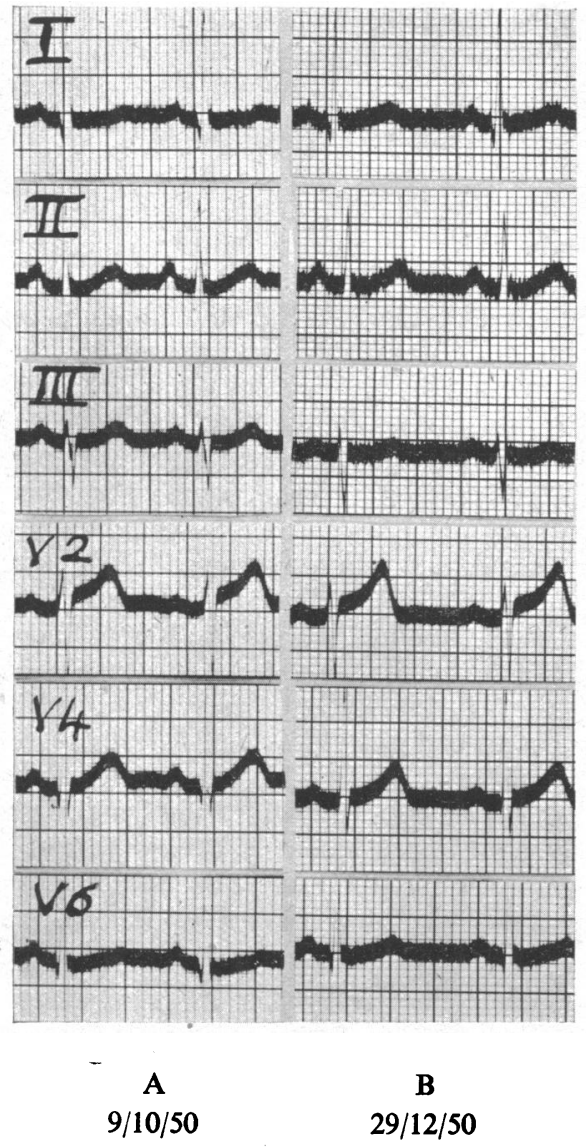

Fig. 1.-Case 1. Impending cardiac infarction. (A) Cardiogram shows abnormally shaped $\mathrm{T}$ waves in leads II and V4 and low $T$ waves in leads 1 and V6. (B) After anticoagulant treatment, reversion to normal patterns in all leads. Clinical details in text.

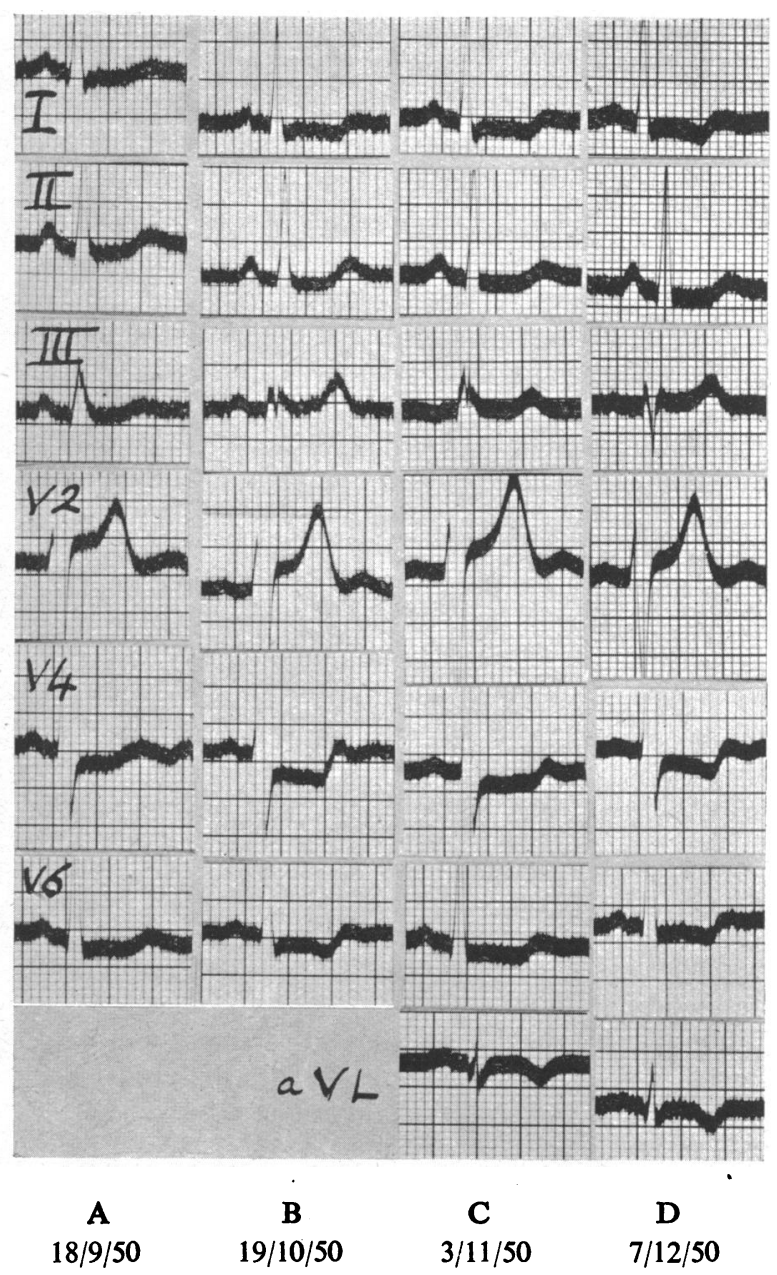

Fig. 2.-Case 3. Angina of effort becoming more frequent and severe. (A) S-T depression in leads I, II, V4, V6, and $2 \mathrm{~mm}$. elevation in V2. (B) After 2 weeks bed rest. Tromexan started 27/10/50; thereafter only one bout of pain. (C) Reversion towards normal but aVL abnormal. (D) Curves unchanged; had walked half mile without pain.

Case 6. A man, aged 67, had cardiac infarction in 1941; this and a complicating pulmonary infarct kept him in bed for six months. A transient pain had occurred fourteen days before the new seizure which started during sleep in the early hours of 8/3/50; it was agonizing and radiated from the chest to both arms, lasting ten hours. After admission to hospital anticoagulant treatment was started with heparin for three days and continued with dicoumarol for four weeks. Nocturnal pains recurred during the first week. Blood pressure during the major attack was 140/90; it fell to $115 / 85$ during the next few days and rose to $140 / 90$ in the course of four weeks. There was no fever; the E.S.R. was never raised. Cardiogram $(9 / 3 / 50)$ showed the patterns characteristic of old apical infarction of the heart; a further record on $23 / 3 / 50$ showed identical patterns. The patient made an uneventful recovery but remained liable to angina of effort and rest.

Case 7. A business man, aged 49, had a cardiac infarction in February, 1946, and a much more severe bout in September, 1949. Since then he had been liable to pain on slight effort or emotion. On 15/2/51 he attended the hospital having had recurrent pains at rest for seven days. Cardiogram (Fig. 4A) showed a 


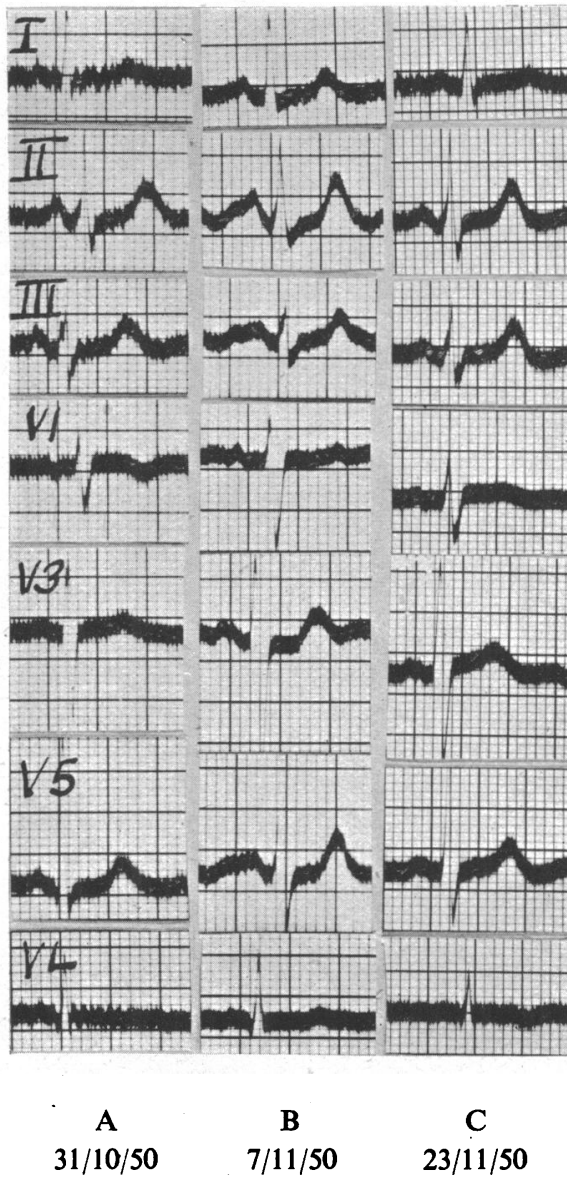

Fig. 3.-Case 5. Worsening angina of three days duration at time of first record. (A) Slight ischæmic change, notably suppression of $T$ in aVL. (B) Absence of improvement after bed rest one week later: $\mathrm{S}-\mathrm{T}$ depressions appearing in leads II and V3. (C) After three weeks anticoagulant treatment: no further pain and regression of ischæmic patterns although $\mathrm{T}$ now inverted in aVL.

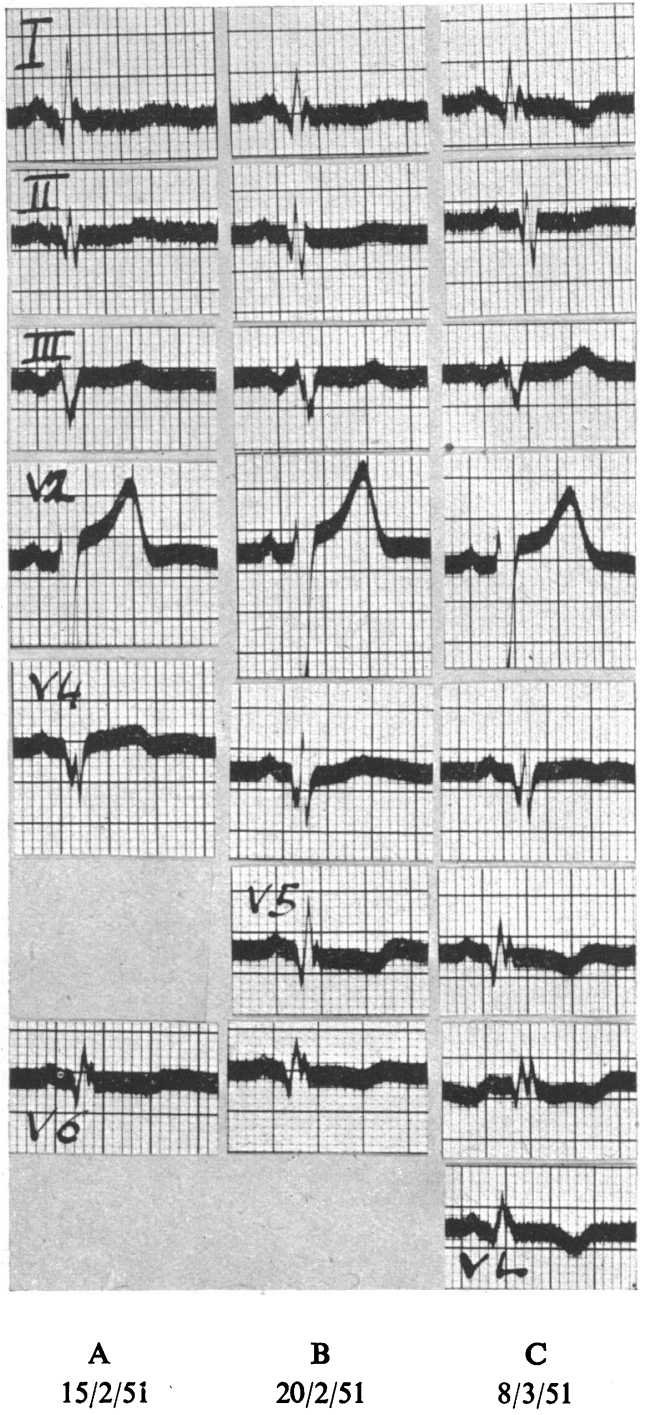

Fig. 4.-Case 7. Two previous cardiac infarctions. (A) After one week of rest angina: humped elevation of S-T in V4. (B) After three days anticoagulant treatment: improvement in V4: no further pain. (C) After 19 days treatment, graph showed that a slight cardiac infarction had been sustained but a severe illness and a third gross lesion seemed to have been averted.

humped and elevated S-T segment in V4. He was admitted two days later and anticoagulant treatment was started. For two days there was fever and the E.S.R. was elevated. On 20/2/51 a new graph showed no significant changes (Fig. 4B). Forty-eight hours after treatment was started the patient became free from pain and he had no further attack while in hospital. The last cardiogram on $8 / 3 / 51$ showed inversion of the $T$ wave in leads I and aVL with splintered ventricular complexes in leads I, V5, and V6 (Fig. 4C). He had thus sustained a slight antero-lateral extension but the development of a gross lesion seemed to have been prevented. 


\section{Unsuccessful Attempts to Prevent Infarction by Anticoagulant Treatment}

In seven instances anticoagulants were unavailing in forestalling infarction of the heart. These patients were mostly afflicted with severe and extensive arterial and, especially, coronary disease. Cardiac infarction occurred in three cases after four or five days treatment. In a fourth death took place four days after starting treatment. In another case, anticoagulants had to be discontinued after ten days and three weeks later cardiac infarction developed. The circumstances of the two remaining cases were as follows.

Case 13. A woman, aged 67, had been getting short of breath on exertion and angina of effort had supervened. She was found to have a high blood pressure but the cardiogram showed only left ventricular stress (Fig. 5A). With rest in bed in hospital and on treatment with heparin she at first improved, the graph showing inversion of $\mathrm{T}$ waves in CR2 (Fig. 5B). However, after a week's treatment she developed acute cardiac infarction from which she died twenty-four days after admission to hospital (Fig. 5C). Necropsy showed very extensive thinning of about two-thirds of the wall of the left ventricle, in which little muscular tissue remained except in the proximal part and posteriorly. The distribution of the coronary arteries was anomalous and the vessels showed advanced atheroma with calcification and recent thrombus formation.

Case 14. A woman, aged 62, had been troubled for a year with angina of effort. For a month before she came under observation on 4/12/50 attacks had recurred more frequently and there had been rest pain and nocturnal attacks. B.P. 160/105. Normal rhythm, 80 a minute. Cardiogram showed slight $\mathrm{S}-\mathrm{T}$ depression in leads I, II, and CR6. Diagnosis: mild hypertension and myocardial ischæmia. Intramuscular heparin was started on 6/12/50 and on the whole the anginal pains became less. On re-examination on 16/12/50 the blood pressure had fallen to 120/75; accentuation of the pulmonary second sound and some rales at the bases pointed to left ventricular failure. The graph now showed characteristic patterns of antero-lateral cardiac infarction of slight degree. On $21 / 12 / 50$ the white cells numbered 11,000 , of which 80 per cent were polymorphs. E.S.R. $8 \mathrm{~mm}$. The patient made an uneventful recovery.

A

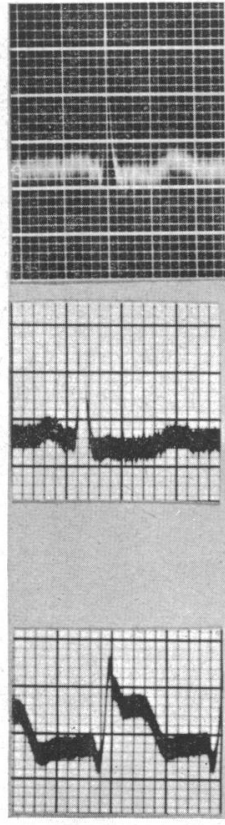

I
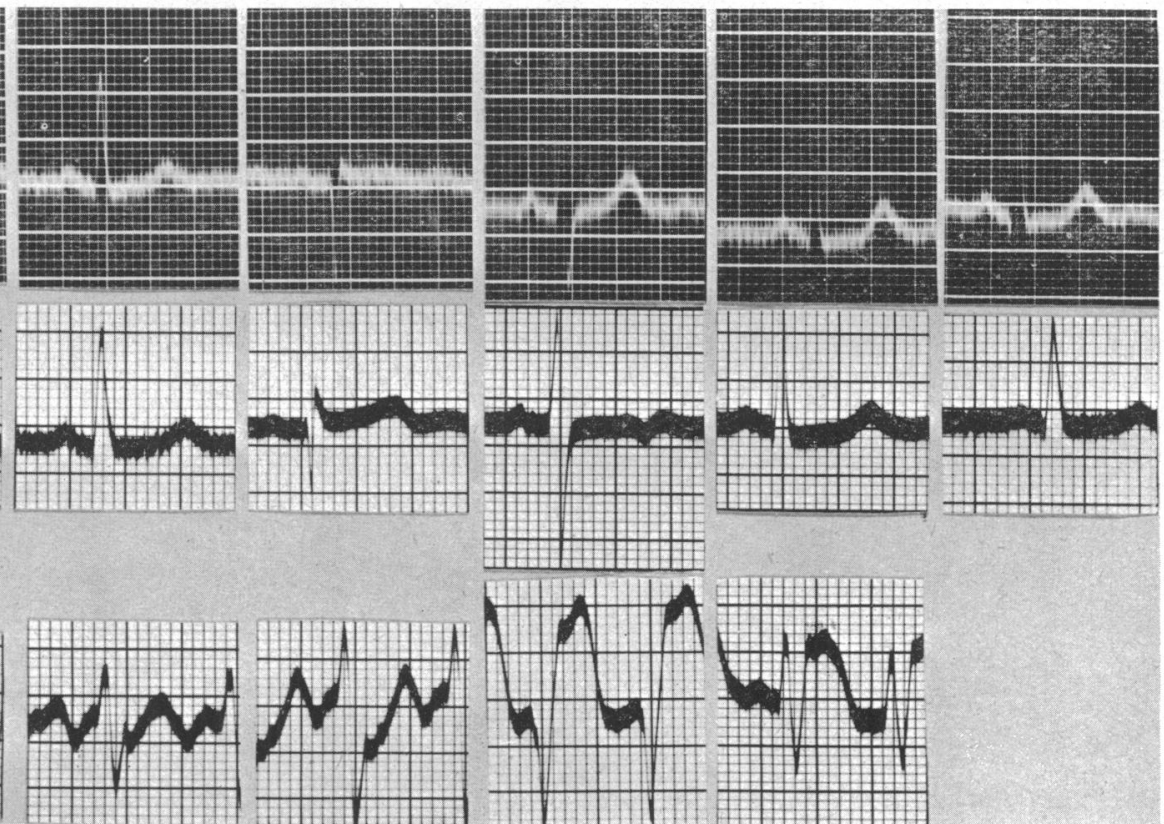

II

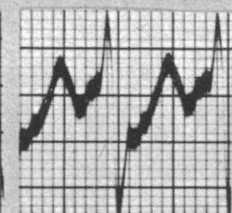

III

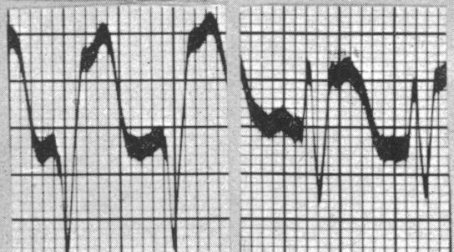

CR2

CR4
CR6

FIG. 5.-Case 13. Hypertension and angina of effort. (A) Graph showing only left ventricular stress. (B) Clinical improvement followed rest and heparin but pattern of myocardial ischæmia in CR2. (C) Despite treatment fatal acute cardiac infarction developed. Necropsy showed long-standing and extensive ischæmic damage in contrast to relatively normal initial cardiogram (A). 


\section{Discussion}

Irrespective of the existence or otherwise of a previous anginal history, a patient who has steadily worsening cardiac pain is likely to develop infarction of the heart. It has been shown that in 15 per cent or more of cardiac infarctions of all grades a premonitory syndrome led up to the acute occlusion. It has been customary, long before the introduction of anticoagulants, to treat worsening angina by rest in bed but only too often this has failed to avert myocardial infarction. In our Cases 1,4 , and 5 the failure of rest to check the increasing pain of a waning coronary supply was an outstanding feature. Moreover, appeal to clinical experience suggests that a minority of patients with typical prodromal pain do not develop cardiac infarction, a course of events exemplified in Cases 15 and 16. In Case 15, a man who had been afflicted with angina for fifteen years had several phases of exacerbation in which the occurrence of increasing pain and nocturnal attacks seemed to herald an acute occlusion but only on one occasion (three years ago) was this expectation borne out by slight posterior infarction; this incidentally served to prove the cardiac origin of the pain. In another example (Case 16), a business man began to have angina of effort at the age of 48; during the 17 years that have elapsed there have been periods of a week or two when pains had become more severe, half a dozen or more times in the day and losing their relation to effort and even waking the patient from sleep. He has never consented to rest more than briefly for these troubles but on at least four occasions cardiac infarction was expected but did not happen; he did have one posterior infarction, not of severe degree, ten years ago. In a third instance (Case 9) a man, aged 68, who was gradually losing his sight, developed worsening angina. After rest in bed and sedatives (but no anticoagulant treatment) the general condition improved and the pain lessened. Cardiography showed S-T depressions in leads II, and V4-V6 with slurring of QRS in V3, V7, and V1, suggesting nothing more than a sub-endocardial ischæmia; no evidence of infarction ever appeared and a good recovery was made. The eye condition, however, caused such depression that the patient hanged himself. The coroner's post-mortem revealed serious coarse scarring of the myocardium due to coronary occlusion by lightly calcified atheroma; there was no fresh disease. These findings endorsed the clinical impression that the prodromal syndrome had not culminated in infarction.

\section{Diagnosis AND TREATMENT ÓF IMPENDING CARDIAC INFARCTION}

The diagnosis of impending coronary occlusion is more clinical than instrumental; in fact, the cardiogram shows only slight changes similar to those found in a positive effort test. Thus it cannot be predicted from the record if infarction is going to take place or not. In fact, when cardiographic changes appear, infarction may already have taken place (as in Case 3) but even then treatment may avert the extension of it. A normal cardiogram is compatible with extensive coronary changes, as shown in Case 13, and this may well explain the failure in such a case of any treatment to prevent cardiac infarction.

Now that in one out of five or six cases of cardiac infarction there is a recognizable warning, an opportunity is provided for preventive treatment. It has been seen that rest, sedatives, and vasodilators have failed to ward off the myocardial damage that generally follows. The indications, then, for the use of any medicament that will hinder clotting are plain to see, and this situation constitutes the reasonable basis for the prophylactic use of heparin and dicoumarol. The histories of Cases 1-7 lend support to this method of treatment as in these patients by all usual standards and on the basis of clinical experience, the culmination in acute coronary occlusion was more than likely. Yet in none of them was there evidence of more than localized subendocardial ischæmia.

The principal argument against the use of anticoagulants in any circumstances is the risk of hæmorrhage in a dangerous situation. Such a risk is slight if proper methods and precautions are used; it is obviously to be accepted wherever there is reasonable expectation of warding off a likely serious or even fatal development. Thus this risk is taken when anticoagulants are used to ward off 
post-operative thrombosis and embolism and to forestall mural venous thrombosis in severe cardiac infarction. The justification for their use in trying to prevent cardiac infarction is not less; perhaps it is greater since it cannot be argued in these circumstances that the disturbance occasioned by injections and the taking of blood samples in a seriously ill patient offsets any hypothetical gain.

\section{SUMMARY}

Reference is made to the prodromal syndrome of cardiac infarction in which anginal pain alters its pattern and worsens. The recognition of the strong likelihood that cardiac infarction will follow such premonitory pain offers a prospect of preventive treatment by anticoagulants.

An account is given of fourteen patients presenting this prodromal syndrome who were treated by heparin and dicoumarol. In seven instances such-treatment coincided with progressive improvement; in six no infarction developed and in the seventh the ensuing infarct was slight although previous infarctions had been severe. From the first few days of treatment there seemed to be a turning point, progressively worsening pain that had resisted rest and other medicaments giving way to diminution and final disappearance of pain. In the other seven patients, cardiac infarction developed in spite of treatment. Three of this group died and necropsy in two of them showed extremely advanced coronary sclerosis and ischæmia involving a large part of the myocardium. In one of these patients an electrocardiogram before infarction showed only minimal abnormalities representing subendocardial ischæmia in spite of the existence of widespread coronary arterial narrowing. This may explain the failure of preventive treatment in some patients who have normal or almost normal electrocardiograms.

We are indebted to Miss Anne Snaith, Cardiographic Technician to the Hospital, for some of the electrocardiograms and for the mounting.

\section{REFERENCES}

Abrahams, D. G., and Howarth, S. (1950). Brit. Heart J., 12, 429.

Allen, Hynes, Koale, and Barker, N. W. (1947). Ann. intern. Med., 27, 371.

Behrmann, J. H., Hipp, H. R., and Meyer, H. E. (1950). Amer. J. Med., 9, 156.

Brill, I. C. (1938). Ann. intern. Med., 12, 365.

Cotlove, C., and Vorzimer, J. J. (1946). Quoted by Nicol and Fassett, (1947).

Feil, H. S. (1937). Amer. J. med. Sci., 194, 42.

Holtzman, M. (1948). Cardiologia, 13, Fase. 4, 177.

Hyman, J., and Harris, R. (1950). Amer. Heart J., 39, 321.

Kahn, M. H. (1926). Amer. J. med. Sci., 172, 418.

Levine, S. A. (1929). Medicine, 8, 245.

Mounsey, P. (1951). Brit. Heart J., 13, 215

Nichol, E. S., and Borg, J. F. (1950). Circulation, i, 1097.

- and Fassett, D. W. (1947). Southern med. J., 40, 631.

Palmer, J. L., and Gunderson, S. M. (1948). New England J. Med., 239, 818.

Papp, C., and Shirley Smith, K. (1951). Brit. Heart J., 13, 17.

Parker, R. L. and Barker, N. W. (1948). Proc. Staff Meet. Mayo Clin., 23, 367.

Parkinson, J., and Bedford, D. E. (1928). Lancet, 1, 4.

Plotz, M. (1944). N.Y. State J. Med., 44, 1227.

Reich, C., and Eisenmenger, W. (1948). Amer. J. med. Sci., 215, 617.

Sampson, J. J., and Eliaser, M. (1937). Amer. Heart J., 13, 675.

Shirley Smith, K. (1950). Brit. Heart J., 12, 428.

Solandt, D. Y., and Best, C. H. (1938). Lancet, 2, 130.

Wearn, J. J. (1923). Quoted by Feil (1937).

Willius, F. A. (1936). Proc. Staff Meet. Mayo Clin., 11, 414.

Wood, P. (1949). Brit. med. J., 1, 26.

(1950) Diseases of the Heart and Circulation. London.

Wright, I. S., Marple, C. B., and Beck, D. F. (1948). Amer. Heart J., 36, 801.

-, (1949). Ann. intern. Med., 30, 80. 